\title{
Selecting Chickens for Home Use
}

\author{
Ralph A. Ernst, Extension Poultry Specialist, \\ Francine A. Bradley, Extension Poultry Specialist \\ and Gary Beall, Communications Specialist, University of California, Davis
}

Raising chickens can be fun and educational for the entire family. The kind of chickens you select for home use will depend on whether you want eggs, meat, or exhibition stock. Regardless of whether you are establishing your first flock or already have chickens, here are a few guidelines on selecting and replacing stock that can make your enterprise more efficient and enjoyable.

\section{STOCK FOR EGG PRODUCTION}

Most people keep chickens to provide fresh eggs for home use. Hens from breeds and varieties such as Rhode Island Red, New Hampshire Red, and SingleComb White Leghorn can be used for egg production, but if you want maximum egg production for your investment it is best to purchase the kind of chickens that commercial producers use. Commercial egg-laying stock is produced by crossing two or more White Leghorn lines that have been selected for high egg production, egg quality, large egg size, small body size, and resistance to disease.

You also can get excellent commercial strains that produce brown eggs. These are usually crosses of commercial lines developed from two different breeds and varieties, such as the Rhode Island Red, Barred Plymouth Rock, or New Hampshire Red.

Most hatcheries and some feed stores either carry commercial strains of chickens or are able to get them for you upon request. A single breed or variety may be available under a number of trade names.

If adults of these commercial strains are mated, their offspring will not have all of the desirable traits present in the parents, so for maximum performance you should purchase chicks from the hatchery rather than raise your own replacement stock.

\section{STOCK FOR MEAT PRODUCTION}

As is the case for egg producers, the kind of chickens used by commercial meat producers have been selected for their advantageous characteristics: in this case, fast growth and efficient feed utilization. The most common commercial meat chicken is a cross between selected lines of White Plymouth Rock hens and White Cornish cocks. With good management, chickens from these crosses will weigh 5 to 6 pounds and make excellent fryers by the time they are 7 weeks old. An additional 3 weeks' growth will give you roasting birds that weigh from 7 to 10 pounds. This same cross is used commercially to produce Rock-Cornish game hens, which are slaughtered at a younger age. Chickens selected specifically for meat production eat a lot of feed and are poor layers, so it is not economical to keep these hens for egg production.

Some consumers prefer the meat from slower-growing breeds. Breeds such as New Hampshire Red or White Plymouth Rock grow more slowly than commercial meat crosses and are probably easier for inexperienced growers to manage. The chicks of these breeds often require ten weeks or more to reach three pounds in weight.

\section{STOCK FOR EXHIBITION}

Many people enjoy breeding poultry and developing various breeds and varieties for exhibition in fairs or poultry shows. This hobby requires skill in breeding and knowledge of how to prepare stock for exhibition. It is something you probably should not get into until you are familiar with the basic procedures necessary for successful chicken husbandry.

The best way to become acquainted with exhibition stock is to attend some poultry shows where you can see how different chickens perform and are judged. You can often buy stock at these shows, but remember that exhibition stock varies in quality (trueness to standard descriptions), and it takes experience to judge quality. Commercial (egg-laying or meat) stock can only be exhibited in commercial or utility classes.

You can find descriptions of the recognized breeds and varieties of large and bantam chickens in the American Poultry Association publication The American Standard of Perfection. Bantams (smaller poultry) also are described in detail in the American Bantam Association's Bantam Standard.

For these publications or more information on raising poultry for exhibition, contact the American Poultry Association, Inc. (Lorna Rhodes, Secretary-Treasurer, 133 Millville Street, Mendon, MA 01756) or the American Bantam Association (Eleanor Vinhage, Secretary, P.O. Box 127, Augusta, NJ 07822). There also

University of California - Division of Agriculture and Natural Resources Publication 7232 (formerly 2894) 
are many local poultry clubs that sponsor poultry shows and provide other services for their members. Through contacts like these, the beginner can learn much about the art of breeding fancy chickens.

\section{BUYING YOUR CHICKENS}

One-day-old chicks are the most economical and safest to buy. You can obtain them from commercial hatcheries or from many feed stores, either straight-run (both males and females) or sexed. You can also get them from a friend, neighbor, or just about anyone else who has a backyard flock and is hatching a few chicks for sale. Use these sources with caution, however, since you may be bringing disease problems home along with your chicks. Be sure to request that your chicks be from Pullorum-typhoid clean stock (hatcheries that are members of the National Poultry Improvement Plan must have their flocks tested for these bacteria) and that they be vaccinated against Marek's Disease. Otherwise, these diseases can cause considerable losses among your stock. The vaccination for Marek's Disease can only be successfully administered on the day the chicks hatch.

Egg production stock sometimes can be purchased as started pullets between 6 and 22 weeks of age. Older hens discarded by commercial producers also may be available. The purchase price will vary with the age, breed, and strain of the birds and their potential production life. Commercial hens are often retained until they are 30 months old; at this age they are a poor choice for starting a home poultry project.

\section{HATCHING YOUR OWN CHICKS}

If you already have chickens, you may want to have the experience and fun of producing your own replacement stock, either by a setting hen or artificially incubating eggs. In either case, you will need a rooster for every 7 to 10 hens in your flock. If you use natural reproduction, you also will need a broody hen for setting. These hens are easily recognized by their behavior. They spend most of their time on the nest, and when approached they ruffle their feathers and cluck repeatedly. You can encourage broodiness by leaving real or imitation eggs in the nest.

Prepare a nest for the broody hen that is well bedded with rice hulls, wood shavings or straw, in a quiet and secluded area. Darken the nest by partially closing the entrance with a plastic, cloth, or canvas flap. Put as many eggs in the nest as your hen can cover comfortably (8 to 10 for a medium-sized hen) and then allow the hen to start setting. To be sure you have selected a consistent setter, take her off the nest a few times and see if she returns promptly to the nest. Be sure to provide feed and water close to the nest. It is advisable, but not essential, to separate setting hens from the rest of the flock. The eggs should hatch in approximately 21 days.

If necessary, you can accumulate eggs for 7 to 10 days before setting, but remember that the hatch will decline as storage time increases. Keep hatching eggs in a cool place $\left(50^{\circ}\right.$ to $75^{\circ} \mathrm{F}\left[10^{\circ}\right.$ to $\left.\left.24^{\circ} \mathrm{C}\right]\right)$-never in a household refrigerator.

To artificially incubate eggs, you can either purchase or build an incubator that will replace the function of the setting hen. Instructions on how to use the incubator are usually furnished when you purchase an incubator or incubator kit.

\section{REPLACING YOUR STOCK}

Since feed is the biggest cost in producing your own eggs, it is best to manage your flock for efficient egg production. Pullets begin laying when they are 16 to 25 weeks old and production peaks when hens are about 30 weeks old. Then it declines steadily (about $1 / 2$ percent per week) until the hens molt or the flock is replaced.

As egg production declines, the egg shells will become rougher and weaker, the egg whites will become thinner, and the yolk membranes will become weaker. Since egg numbers and quality both decline as the flock ages, it is usually advisable to replace the flock with pullets about once a year.

If your goal is efficient egg production, you should also remove non-layers and slaughter them for eating as your flock grows older. Older hens do not make good frying or roasting chickens. However, if you have the time to cook them slowly and for several hours, they will make a very flavorful soup. Use the following characteristics to differentiate layers from non-layers.

\begin{tabular}{cll}
\hline $\begin{array}{l}\text { Physical } \\
\text { characteristic }\end{array}$ & Layers & Non-layers \\
\hline $\begin{array}{c}\text { Comb \& } \\
\text { wattles }\end{array}$ & $\begin{array}{l}\text { large, red, } \\
\text { waxy, full }\end{array}$ & $\begin{array}{l}\text { small, pale, } \\
\text { shrunken }\end{array}$ \\
Vent & $\begin{array}{l}\text { large, moist, } \\
\text { bleached }\end{array}$ & $\begin{array}{l}\text { dry, puckered, } \\
\text { yellow }\end{array}$ \\
Abdomen & $\begin{array}{l}\text { full, soft, } \\
\text { pliable }\end{array}$ & $\begin{array}{l}\text { shallow or } \\
\text { full of fat }\end{array}$ \\
& flexible, wide & $\begin{array}{l}\text { stiff, close together } \\
\text { (2 or more }\end{array}$ \\
Pubic & fingers apart) 2 fingers \\
bones & apart) \\
& no molting, & molting, growing \\
Feathers & no new feathers & new feathers \\
\hline
\end{tabular}


A large, moist, bleached vent and open, flexible pubic bones are the most reliable indications of laying. Molting may be an indication that the hen has stopped laying, but always check the vent and pubic bones before culling her. Good layers often have worn and missing feathers.

When you catch hens to look for non-layers, take care not to injure or panic the flock. A chicken-catching hook or large fishing net can be used to catch the birds safely.

By the time your flock is a year old, the number of hens should be reduced considerably by culling and "normal" death losses. Normal yearly deaths usually range from 5 to 15 percent of the flock. Final depletion can be accomplished by increased culling near the end of the year and, finally, by selling or slaughtering the remaining hens.
Before bringing new chicks or pullets in, you should clean out your chicken house and pen. If you've had a disease problem with your previous flock, you should also thoroughly disinfect the chicken house and equipment.

Some owners of small flocks keep their stock for several years, periodically adding pullets. This is an undesirable practice in terms of efficiency, since mixing pullets with mature hens may result in fighting and cannibalism, and chances of a disease problem increase. Also, you would have to put up with unproductive molting periods and decreased overall production from the older hens.

\section{HELPFUL PUBLICATIONS}

Starting and managing small poultry units. UC DANR Leaflet 2656. 